\title{
Overcoming Physical Separation in the Online Environment to Help Learners Persist
}

\author{
Tina Stavredes, PhD \\ Chair, Psychology, School of Undergraduate Studies \\ Capella University
}

\begin{abstract}
Academic leaders at all types of institutions report increased demand for face-to-face and online courses, with those at public institutions seeing the greatest impact. In all cases, the demand is greater for online offerings than for the corresponding face-to-face offerings (Allen \& Seaman, 2009). In addition, students are increasingly demanding more opportunities to take courses online to accommodate their busy lifestyles. With this increased demand, more faculty are being asked to teach online. One of the challenges of teaching in the online environment is the physical separation of the instructor and learner. Faculty teaching face-to-face depend on the opportunity to look at a learner's expression to see whether he or she understands course materials. The lack of visual contact in the online environment becomes a barrier for teaching.

According to Michael Moore (1980), transactional distance, which relates to physical separation in the online environment, can have an impact on understanding and perceptions, which in turn can affect student motivation. The physical separation can lead to psychological and communications gaps that can result in decreased presence, misunderstandings, and low engagement owing to the absence of visual cues to guide the learner. Overcoming transactional distance requires specialized organizational and teaching procedures. Teaching variables associated with transactional distance include dialogue and structure. Dialogue is the interaction between the instructor and learner; structure relates to the design of the course, including the content, navigation, multimedia, and communication tools used to support the online environment. To minimize transactional distance, it is important that the structure of the

Active learning requires learners to think critically and reflect on what they know, as they actively engage in learning activities to make meaning from the content and construct knowledge. The learner is thereby moved away from being extrinsically motivated and focused on grades to becoming more intrinsically motivated, with a focus on learning.
\end{abstract} course have a high degree of flexibility. According to Moore (1980), increased dialogue between the instructor and learner, along with a flexible learning environment, leads to low transactional distance.

In the online environment, where there is no face-to-face interaction, much effort is required to develop presence between learners and with the instructor. For learners moving from the face-to-face to online environment, the void due to the lack of physical presence can lead to feelings of isolation, which can have a negative impact on motivation and persistence. In addition, the lack of presence can impact the development of higher order thinking skills, a process that requires collaboration. According to Garrison, Anderson, and Archer (2001), learning occurs within a community of inquiry through the interaction of three kinds of presence: social, cognitive, and teaching. Social presence establishes learners as individuals who are available to engage in learning; cognitive presence is the ability of learners to construct knowledge through peer-to-peer interactions; and teaching presence is the means by which the instructor facilitates the online learning environment to support social and cognitive presence and to help learners meet the outcomes of course activities.

A structure that supports social presence in the online environment can help reduce isolation and establish learners as being present and available for InSight: A J ournal of Scholarly Teaching 
interactions. Kerhrwald (2008) defines social presence as "an individual's ability to demonstrate his or her state of being in a virtual environment and so signal his or her availability for interpersonal transactions" (p. 94). Without the awareness of learners' presence, it is nearly impossible to develop relationships. To develop social presence, the design of the online environment must include opportunities for all to engage in social dialogue and get to know one another. This can be done through discussions that allow learners an opportunity to introduce themselves to one another, or through a cyber cafe or lounge area that provides learners an opportunity to engage in casual dialogue not associated with the course content. As learners begin to engage socially with the instructor and peers, they can build trust in one another and begin to develop a sense of community that prepares them for engaging in a community of inquiry as they participate in course activities.

According to Short, Williams, and Christie (1976), when communication channels are increased, social presence increases among peers and the instructor; whereas, when communication channels are reduced, social presence decreases among peers and the instructor. A variety of communication tools can be used in the online environment to increase presence, including email, private journals, discussion forums, instant chat, web conferencing, and microblogs. Reaching out to learners individually via email or a private journal acknowledges the instructor's awareness of their presence in the course and opens lines of communication for the learner to begin a dialogue to share feelings and ask questions. Discussion forums provide an opportunity for learners to engage in dialogue that is casual or topicspecific. Instant chat can help signify a learner's presence, when he or she is online in the course environment, and invite dialogue with other learners or the instructor when they are actively engaging online in course activities. Web conferencing can provide opportunities for the instructor to engage either with learners as a group to deliver lectures to or answer questions from, or with individual learners to help them overcome navigation or technical problems that require visual interactions. Microblogs such as Twitter provide a means for instructors to communicate just-intime with learners about upcoming due dates or other short messages that are time sensitive. Twitter can also provide a venue for learners to engage in just-in-time communications with the instructor or other members of the course. Opportunities to minimize the isolation of the online environment and allow learners to develop greater presence can lower the transactional distance of an online course, potentially leading to greater persistence and the achievement of course goals.

Structuring the online environment to support cognitive presence is also critical. Cognitive presence is developed as learners engage in discourse and share their knowledge, experience, and ideas to construct knowledge. Garrison et al. (2001) define cognitive presence as "the extent to which the participants in any particular configuration of a community of inquiry are able to construct meaning through sustained communication" (p.5). This requires that the online experience be designed for "active learning" that places the responsibility of learning and acquiring knowledge on the learner. Active learning requires learners to think critically and reflect on what they know, as they actively engage in learning activities to make meaning from the content and construct knowledge. The learner is thereby moved away from being extrinsically motivated and focused on grades to becoming more intrinsically motivated, with a focus on learning. Cognitive presence in the form of active learning is transformative because it focuses on meaningmaking that is relevant to the learner's life personally and professionally, which has a positive impact on persistence.

The structure of course activities can support active learning. Discussions should focus on topics that require learners to think critically. The more structure that can be provided to discussion activities, the more opportunities learners will have to build critical thinking skills and develop an engaging community of inquiry. Criteria for discussions should focus on the elements of critical thinking, as well as on the expectations for engaging in discussions in a timely manner and for interacting with peers. Course activities should support active learning by providing 
opportunities for learners to develop an understanding of how to use an active knowledge base by "calling into question the assumptions underlying their customary, habitual ways of thinking and acting and then being ready to think and act differently on the basis of this critical questioning" (Brookfield, 1987, p. 1).

The flexibility of the learning transactional distance, depending on the individual learning styles of learners. Some learners may require more structure to support their dependent learning styles, whereas others may be more self-directed and prefer independent learning experiences (Stavredes, 2011). The critical component of the structure is the flexibility to meet the individual needs of learners. Dependent learners will require more support to accomplish learning activities. Checklists can help them accomplish weekly

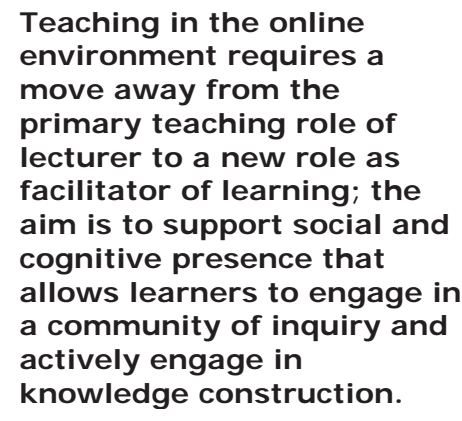

tasks in the course and support their planning processes. Templates and worksheets help dependent learners understand how to accomplish specific tasks and monitor their learning. Reflective exercises can encourage them to evaluate their learning. Additionally, support resources can help them fill gaps in knowledge and skills. Independent learners, on the other hand, prefer to work alone. They may find some activities to be boring and repetitive, so providing a degree of flexibility to meet their needs is important. This can include allowing them to choose topics of interest to them personally and developing projects that allow them to have a certain degree of autonomy.

Teaching presence, the third and last type of presence, is critical to learner success. End-of-course evaluations from learners focus on the interactions they have with their instructor; complaints generally include comments regarding the lack of instructor presence. Teaching in the online environment requires a move away from the primary teaching role of lecturer to a new role as facilitator of learning; the aim is to support social and cognitive presence that allows learners to engage in a community of inquiry and actively engage in knowledge construction. The instructor role should include interactions to encourage participation and knowledge construction. The instructor should also monitor learner progress, provide formative feedback, and evaluate learner performance through summative feedback. Interactions should also encourage learners to be more self-directed.

To encourage participation, the instructor should reach out to learners personally to open up communication channels and establish trust. The acknowledgement of the learner personally also may contribute to learner accountability. The instructor should also encourage knowledge construction by keeping discussions interesting, motivating, and focused on the topic. The instructor can use prompts to encourage discussions and ask learners to elaborate on discussion posts when they don't meet the requirements of the discussion. When a learner has a narrow focus or opinion, the instructor can take on another perspective and challenge the learner's perspective or ask the learner to take on another perspective to help him or her look at the issue from a different viewpoint. Instructors can encourage learners to discuss the assumptions or implications of their line of reasoning. The instructor can also use weaving techniques throughout a discussion to develop an understanding of the diversity of opinions and different lines of reasoning of learners on the issue, as well as help re-focus the discussion if it moves off topic. The instructor who participates as an equal in the discussion and contributes their opinions can influence the thoughts of learners; so at the end of a discussion, the instructor can summarize the conversation and include his or her personal opinion and experience to provide additional insight on the issue.

It is essential that the online instructor monitor learner progress towards goals. Formative feedback allows learners an opportunity to improve performance along the way. In addition, it is important to point out writing issues to help

InSight: A Journal of Scholarly Teaching 
learners overcome them early in the course, before major writing assignments are due. The instructor should also monitor individual learner activity and proactively reach out to inactive learners to re-engage them in the course. Monitoring the course environment for behavioral issues and quickly stepping in is crucial to ensuring that improper behavior is curtailed and that learners see the instructor is in control of the course environment. Learners want frequent feedback that is timely, specific, and actionable, so feedback should be provided throughout the course. Scoring guides and grading rubrics can provide important information to learners about the expectations of a graded activity and can help the instructor provide feedback that is consistent, specific, and actionable. Finally, it is important to continually encourage learners to become more self-directed by first providing them with extra support early in the course, and then gradually removing this. Strategies should be adopted to support the development of metacognitive skills that help the learner plan, monitor, and evaluate their learning in an online environment that is more suitable for learners who are self-directed.

To summarize, the physical separation of learners and the instructor in the online environment can create high transactional distance, which can have a negative impact on learners' ability to persist online and successfully achieve their educational goals. This creates a challenge for teaching and learning online and requires the design of online courses that create opportunities for increased dialogue as well as provide a flexible course structure to meet the individual needs of learners. The course design should encourage active learning and critical thinking, and it should create opportunities for developing social, cognitive, and teaching presence to build a community of inquiry. Overall, the more deliberate the planning of an online course to increase presence, dialogue, and flexibility to decrease transactional distance, the more opportunities learners will have to be a part of a transformative, online learning experience that encourages critical thinking and the social construction of knowledge through a community of inquiry.

\section{References}

Allen, I. E., \& Seaman, J. (2009). Learning on demand: Online education in the United States. Needham, MA: Sloan Consortium.

Brookfield, S. D. (1987). Developing critical thinkers: Challenging adults to explore alternative ways of thinking and acting. San Francisco: JosseyBass.

Garrison, D. R., Anderson, T., \& Archer. (2001). Critical thinking, cognitive presence, and computer conferencing in distance education. American J ournal of Distance Education, 15(1).

Kerhrwald, B. (2008). Understanding social presence in text-based online learning environments. Distance Education, 29(1), 89-106.

Moore, M. (1980). Independent study. In R. Boyd, J. W. Apps, \& Associates (Eds.), Redefining the discipline of adult education (pp. 1631). San Francisco: Jossey-Bass.

Short, J. A., Williams, E., \& Christie, B. (1976). The social psychology of telecommunications. New York: John Wiley \& Sons.

Stavredes, Tina (2011). Effective Online Teaching: Foundations and Strategies for Student Success. San Francisco: Jossey-Bass. 
Tina Stavredes is chair of the psychology program in the School of Undergraduate Studies at Capella University. In her role she manages over 40 remote faculty. In 2010 she received the Harold Abel Distinguished Faculty Award. Previously, she was Director of Curriculum Development for Capella University. Dr. Stavredes holds a PhD in Educational Psychology with an instructional technology emphasis from the University of Minnesota. She has numerous publications and presentations to her credit. She has recently completed a book with Jossey-Bass titled Effective Online Teaching: Foundations and Strategies for Student Success that will be published August, 2011. 